\title{
Effect of Democratic Coaching Style on the Game Strategy of Badminton Players, at
}

\author{
Region, Sukkur-Sindh \\ * Muhammad Hashim Darya \\ ** Nisar Ahmed Khaskheli (Corresponding Author) \\ *** Javed Ali Soomro
}

\begin{abstract}
This examination study was done to recognize the effect of democratic coaching style on the game strategy of badminton players. It was basic to discover the effect of prevalent democratic coaching style inside the educational structured organizations for developing successful inter-collegiate, interdepartment, and inter-varsity level Badminton players. The examination was ensured on two hundred players (boys) related to Badminton-game. The players studying in various degree programs of twenty concerned Colleges of division Sukkur, $(N=100)$ and twenty various departments of teaching $(N=100)$ of Shah Abdul Latif University Khairpur (SALU) took an active part in the examination. The Badminton players evaluated the efficacy of democratic coaches on their game strategy, utilizing the Coaching Efficacy Scale (C.E.S), a review poll. The frequency and percentage were diversely processed with the general means as; 2.37, 2.41, 2.49, 2.37, 2.34, 2.51, which were distinctive essentially from one another. The outcomes demonstrated that the popularity-based democratic coaching style positively affects the game strategy of players to contend in the competitions. Finally, the impact of democratic coaching style on players' game strategy was found to be higher. This data would add to set up between university and between department level badminton programs all the more successfully to chase ability eventually.
\end{abstract}

Keywords: Coaching, Impact Assessment, Badminton-Players.

Introduction

Badminton is a racket sport that is played with a shuttlecock or birdie as a shot and where the players are isolated by a net that partitions the court into halves. Focuses are scored via handling the bus on your rival's side of the court. Badminton is played as an outside game in a few pieces of the world. Be that as it may, to completely make the most of its latent capacity, badminton ought to be played inside where the breeze can't bargain the trip of the bus (https://badmintonguide). A critical element of mentors and players is to create an improved presentation and extreme triumphs in the competitions. Badminton could be a game that's widely played throughout the planet. This game is played the least bit levels by the people having an area with various age gatherings (Shariff et al., 2009). This can be a game that's played by racquets to hit a shuttlecock to cross a net fixed on the center of the ground. This game is played most typically in two configurations which are "singles" and "duplicates", singles jointly player for each side, and pairs as two players for every side. Officially this game portrays over the oblong nature as an enclosed. A match comprises the simplest of three rounds of 21 focuses or one round of 21 focuses. There's one official, who assumes employment as in charge of the complete competition and that they may have associates and other arbitrators or colleagues. One umpire who assumes employment is liable for the complete court. There's one referee and his job is to call administration flaws and ten line judges who administer the shuttle cork and also the lines of the court (https: Wikipedia).

Coaching in sports is characterized as a lot of techniques proposed to improve the mentor's capacity to impact the conduct of the entire cap and players all the more adequately (Smith, 2010). Successful instructing changes all through explicit play circumstances as the characteristics of players and the realized circumstances fluctuate (Farrow \& Abernthy, 2003). The relationship of player and

* Department of Physical Education and Sports Sciences, Sukkur IBA University, Sindh-Pakistan

** Center for Physical Education Health \& Sports Sciences, Faculty of Natural Sciences, University of Sindh, Sindh-Pakistan

*** Center for Physical Education Health \& Sports Sciences, Faculty of Natural Sciences, University of Sindh, Sindh-Pakistan 
coach It is not any additional to, or implications of, the method of training, nor is it based on the presentation, age, or sex of the players, but rather is the basis of education. A partnership is deliberately formed by the coach and the contender, which is demonstrated by generating gratitude and perspective for each other as individuals. The mentor and player relationship is rooted in the dynamic, all things considered. (Jowett \& Cockerill, 2002). A noteworthy element of mentors and players is to produce an improved exhibition and extreme triumphs in the competitions. Along these lines an inquiry that has been raising since its beginning by the specialists, mentors, and players that what kind of instructing style or conduct in sports is more compelling (Jowett \& Cocker sick, 2003, Cote \& Gilbert, 2009) The fundamental relationship among mentors and players are seen as crucial for creating and advancing the capability of the major part in the games (Jowett, 2007). Productive training is the ability to treat major parts in befitting habits. Players have recognized the capacities and each legitimacy for his/her uniqueness. Coaches need to differ in their style with every player. A comparative kind of training program sometimes falls short for everybody. Every single player ought to be awakened uniquely (Pilus \& Saadan, 2009). The training assumes an indispensable job in the aptitude advancement of the players of any game and has become a genuine worry for the game's experts, sports associations, and all the divisions which are worried about the field of sports. Better training with a viable style advances the specialized aptitudes and numerous other vital strategies in various games. Also in badminton, the training exhibits a key job for advancing methods, aptitudes, the capacity to contend, the capacity to design a powerful game system, and the effectiveness of better outcomes prompting triumphant positions. The analysts in the field of sports are thoroughly considering it to discover the strategies for instructing. Coaching in sports has been ending up being set of arranging and techniques resolved to upgrade the capacity of the mentor to affect the exhibition of the entire group and players all the more effectively (Smith, 2010). The mentors have different jobs fit as a fiddle of the chief, educator, coach, inspirational, director, guide, and supervisor (Martens, 2012). The instructing is an expert movement that encourages the understudies to partake in an action (McDonell, 2016). In serious games, a mentor assumes a significant job in the "prosperity" and execution of competitors. Prevailing and despotic instructing styles could be a wellspring of worry among competitors, influencing temperament states, and glucocorticoid reaction (Oberle \& SchonertReichl, 2016). Nonetheless, some beneficial outcomes in the indigenous habitat were additionally watched, for example, vulnerability decrease or intragroup consistency improvement concerning social associations, particularly when the social order was unmistakably acknowledged (Magee \& Galinsky, 2008). All things being equal, majority rule instructing could improve and build competitor fearlessness, strength, and execution. Mentors ought to have the option to build up possibilities, keep up the force of the preparation procedure, give the inspiration to learn, and over satisfactory criticism to accomplish better execution (Van Duijvenvoorde, et al., 2016). The Coach groups a capacity to offer an aptitude to instruct people to investigate and guarantee an improvement in various games (Christensen \& Ball, 2016, Dong, \& Lavallo, 2016). Drawn out an introduction to aversive upgrades may hinder the foundation of a parity (e.g., evoking feelings of disappointment, misgiving, and outrage), influencing competitors' variation procedure to rivalry (Keatlholetswe \& Malete, 2019).

The Coaching style and standard strategies have been demonstrated for affecting the recreational level in connection with execution (Campbell \& Sullivan, 2005. The Style and Behavior hypothesis is known as a decent degree of fulfillment, innovativeness, and inspiration as being guaranteed by the law based pioneers with subordinates, performing with enormous energy and force regardless of the accessibility or inaccessibility of the pioneer; despotic pioneers for the most part focusing on a gigantic measure of efficiency. Free enterprise administration is considered relevant anyway driving a group having capability and incited individual (Jung et al., 2008). The administration is actualized in working something at an exceptionally significant level of precision, level of certainty, compassion, be concerned and experienced maybe not the same as a less talented chief, as an individual who doesn't fit to confront administrative issues (Dess \& Picken, 2000). The authority is an individual association where an individual suggests, organizes, encourages, and manages others in the exhibition to accomplish the shared objective. The social understanding of authority is viewed as a legend that exercises to reinforce existing social acknowledgment and structure about the need for a hierarchy of leadership and pioneers in foundations. The initiative is an issue of altering a person's regular shared destinations and empowering them to take the exercises expected to get in touch with them. The capability to affect an individual or bundle towards the 
achievement of a shared objective is obligatory (Khan et al., 2015). A more powerful mentor must consider to be as unmistakable and endeavor to improve the exhibition of every player as per need (Kristiansen et al., 2012).

\section{Research gap}

Indeed, the different examinations have shown in regards to the specific relationship between coaches and the players. It has been seen that the understudy players of Badminton of the Shah Abdul Latif University (SALU) Khairpur belonging to its affiliated colleges who took part in the Badminton competitions during their academic days are seen later on at good positions of participation as in intercollegiate, intervarsity, inter-district, inter-region, interprovincial, Sindh games and at the national level of competitions. The Director of Physical Education working in the Colleges additionally also works as a Coach of different games including Badminton as per their huge experience in sports, at Sukkur-region Sindh. The Coaching style of coaches was observed during inter-collegiate and interdepartment tournaments that they apply democratic style coaching. The players of Badminton at Sukkur locale have been seen as reached great degrees of their games. Continuation of this wonder brought up an issue to discover the reality of the Coach-player relationship fit as a fiddle of coaching sway on player's game strategy.

\section{Methods and Materials}

This examination comprises of the understudy players of Badminton belonging to Shah Abdul Latif University Khairpur-(SALU) and its subsidiary Colleges in the Sukkur region.

\section{Research design}

The detail of Colleges of the University was taken from the main office of the University which monitors the affiliation of colleges with University. All the colleges of the Sukkur area were visited to learn about the accessibility of badminton players through the cooperation of the physical education directors of the colleges concerned.

\section{Population}

The players of Badminton who also were pupils studying in the SALU \& its associated Colleges were the population of the study.

\section{Sampling}

Applying the accommodation testing strategy or technique of convenience-sampling, twenty Badminton teams of twenty those institutions or colleges whose players must have played in any event at least inter-class/ inter-department, inter-collegiate or intervarsity competitions, were chosen as an example of the examination on the proposal of concerned Sports Officials, though from the University side, detail of Badminton players was taken from Sports Section of the University.

\section{Sampling size}

The example size of the investigation was 200 Badminton-players, as 100 from Colleges and 100 from universities.

\section{Limitation of the study}

The investigation was restricted to the understudy players (young men) of Part-I and II of B.A, Part-I \& II of BSC, B. Com part-I, and II of Sukkur and Badminton Colleges (young men) players from different departments of Shah Abdul Latif University, Khairpur studying in bachelor or master programs. The students who were enrolled in colleges and M. in the first year \& inter-schools. M. Phil $\& \mathrm{Ph}$. D were ruled out at university. The Coaching Efficacy Scale (CES; Feltz, et al; 1999) comprising of 5 instructing adequacy areas was utilized as an instrument to gather the information as an organized overview survey.

\section{Statistical Examination}

By applying the Statistical Package of Social Sciences (SPSS), version 22, the frequency, percentage, and mean were determined.

\section{Results}

Cronbach's Alpha test was performed to ensure the collected data. The result of Cronbach's Alpha test was 0.92 and was found to be reliable. Thus; (Table) shows the responses of the players in frequencies, percentages, and means respectively. The examination shows that larger piece of responses is for useful results of impact of democratic coaching on the game strategy of Badmintonplayers with a most extraordinary frequency starting from the outset articulation, $16,8 \%, 49,24.5 \%$, $135,67.5 \%$ with a mean 2.37 , second explanation, $12,6.0 \%, 49,24.5 \%, 105,62.5 \%$ with a mean 2.40 , third item, $7,2.5 \%, 94,47 \%, 101,50.5 \%$ with a mean 2.38 , fourth statement $7,3.5 \%, 73,36.5 \%, 120$, 
$60 \%$ with a mean 2.49 , fifth item $13,6.5 \%, 98,49 \%, 89,44.0 \%$ with a mean 2.37 , sixth item $6,6 \%$, $82,41 \%, 112,56 \%$ with a mean 2.34 and seventh as last thing $3,1.5 \%, 91,44.5 \%, 106,53 \%$ with a mean 2.51 this appraisal detailed implies that there are close productive results of democratic coaching style on the game strategy of Badminton-players, concentrating on respective Colleges and University.

Table-1 shows the responses of the respondents against different variables to find out the effect of democratic coaching on the game strategy of Badminton players.

\begin{tabular}{|c|c|c|c|c|}
\hline Statement & Option & Frequency & Percentage & Mean \\
\hline \multirow{3}{*}{$\begin{array}{l}\text { Democratic considers Power of } \\
\text { opponent }\end{array}$} & Not at all & 16 & 8.0 & \multirow{3}{*}{2.37} \\
\hline & Moderately & 49 & 24.5 & \\
\hline & Extremely & 135 & 67.5 & \\
\hline \multirow{3}{*}{$\begin{array}{l}\text { The Democratic Coach knows the } \\
\text { contest situation }\end{array}$} & Not at all & 12 & 6.0 & \multirow{4}{*}{2.41} \\
\hline & Moderately & 49 & 24.5 & \\
\hline & Extremely & 125 & 62.5 & \\
\hline \multirow{3}{*}{$\begin{array}{l}\text { Democratic coach adjusts to different } \\
\text { Situation of Game }\end{array}$} & Not at all & 5 & 2.5 & \\
\hline & Moderately & 94 & 47.0 & \multirow{2}{*}{2.40} \\
\hline & Extremely & 101 & 50.5 & \\
\hline \multirow{3}{*}{$\begin{array}{l}\text { Democratic Coach Recognizes the } \\
\text { weakness of opponents }\end{array}$} & Not at all & 7 & 3.5 & \multirow[b]{3}{*}{2.49} \\
\hline & Moderately & 73 & 36.5 & \\
\hline & Extremely & 120 & 60.0 & \\
\hline \multirow{3}{*}{$\begin{array}{l}\text { Democratic coach takes Significant } \\
\text { decisions }\end{array}$} & Not at all & 13 & 6.5 & \multirow{3}{*}{2.37} \\
\hline & Moderately & 98 & 49.0 & \\
\hline & Extremely & 89 & 44.5 & \\
\hline Democratic Coach & Not at all & 6 & 6.0 & \multirow{3}{*}{2.34} \\
\hline \multirow{2}{*}{ strength of team } & Moderately & 82 & 41.0 & \\
\hline & Extremely & 112 & 56.0 & \\
\hline \multirow[t]{3}{*}{ Democratic regulates Planning } & Not at all & 3 & 1.5 & \multirow[b]{3}{*}{2.51} \\
\hline & Moderately & 91 & 45.5 & \\
\hline & Extremely & 106 & $\mathbf{5 3 . 0}$ & \\
\hline
\end{tabular}

Table-1 shows that the majority of the respondents have opted extremely in $1^{\text {st }}$ item, $2^{\text {nd }}$ and $7^{\text {th }}$ items and moderately in $3^{\text {rd }}, 4^{\text {th }}, 5^{\text {th }}$, and $6^{\text {th }}$ items respectively which show the closest effect of democratic coaching on the game strategy of Badminton student-players

\section{$\mathrm{H}_{0}$ : Badminton's Democratic Leadership Style does not play a critical role in the strategy of the game.}

This hypothesis was tested with the application of Chi-square and found to be rejected, as the Chisquare statistic of The values of all objects is greater than the Essential Chi-Square Value (5.99) with $\mathrm{df}=2$.

$$
\begin{aligned}
& \mathrm{df}=2 \\
& \chi^{2}=49.040
\end{aligned}
$$

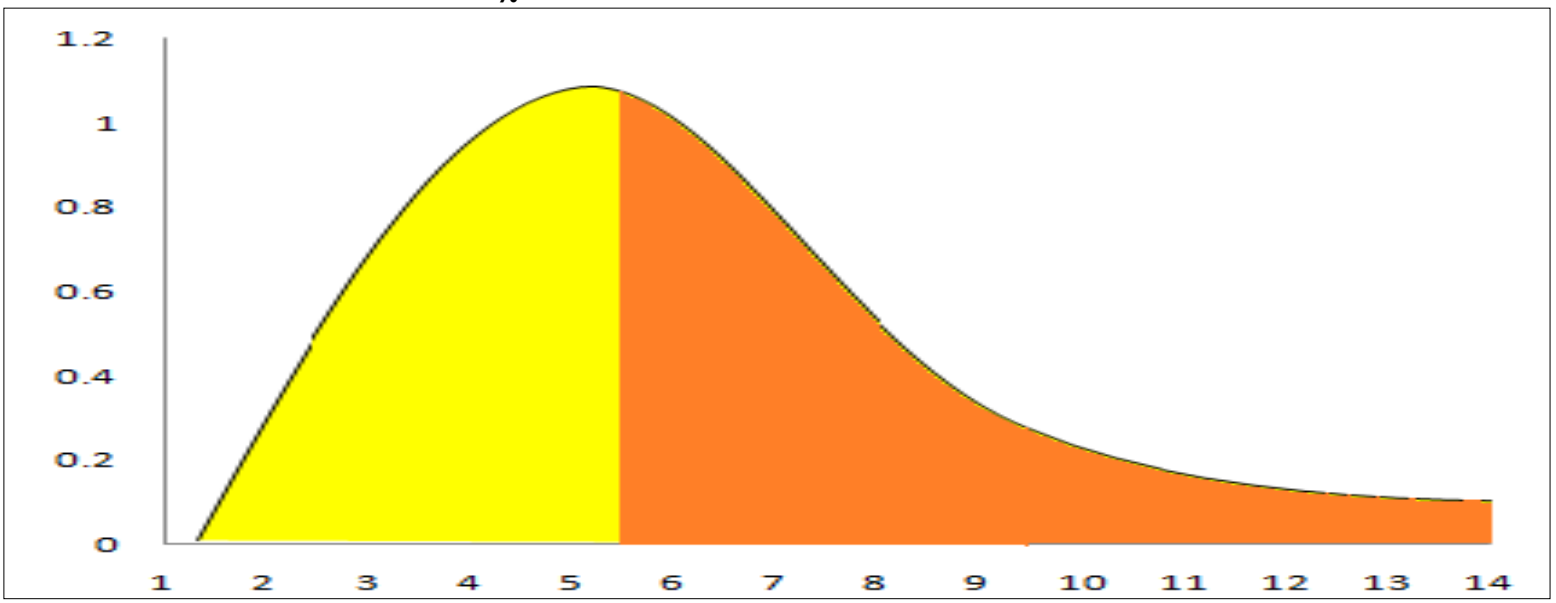

Figure 1. Shows the result of the chi-square test, figure shows that the null hypothesis rejected. 
$\overline{\mathbf{H}_{1}} \quad$ The Democratic style of coaching plays an important role in the badminton players' game strategy.

Alternative hypothesis was tested through chi-square as detail given in (Table 5) with the $\mathrm{P}=$ value of all items was found to be less than 0.5 .

Table 2. Shows the results of chi-square test of hypothesis

\begin{tabular}{|c|c|c|c|c|c|}
\hline Item & observed & Expected & Chi & df & P-value \\
\hline \multirow{3}{*}{1} & 15 & 65.9 & \multirow{3}{*}{112.230} & & \multirow{4}{*}{0.000} \\
\hline & 51 & 65.9 & & \multirow{3}{*}{2} & \\
\hline & 134 & 65.9 & & & \\
\hline \multirow{3}{*}{2} & 12 & 65.9 & \multirow{3}{*}{97.070} & & \\
\hline & 63 & 65.9 & & \multirow{3}{*}{2} & \multirow{3}{*}{0.000} \\
\hline & 125 & 65.9 & & & \\
\hline \multirow{3}{*}{3} & 5 & 65.9 & & & \\
\hline & 94 & 65.9 & \multirow[t]{2}{*}{86.930} & \multirow{3}{*}{2} & \multirow{3}{*}{0.000} \\
\hline & 101 & 65.9 & & & \\
\hline \multirow{3}{*}{4} & 7 & 65.9 & \multirow{3}{*}{95.670} & & \\
\hline & 73 & 65.9 & & \multirow{2}{*}{2} & \multirow{2}{*}{0.000} \\
\hline & 120 & 65.9 & & & \\
\hline
\end{tabular}

\section{Discussion}

Conduct, social and mental outcomes of coaching sway has broadened the focus in ongoing past years with different investigates indicating noteworthy aftereffects of this development for analyzing the effect of mentors' styles on competitors (Feltz et al., 1999) as adjusted by Kavassanu et al., 2008; Myers, et al., 2009. In any case, something imperative which any of past examinations In Sukkur, Sindh, or even in Pakistan, the influence of sports coaching on game strategy and the scale to which they vary from coaching accounts of instructive effects have not been dissected on this. There should hardly be a hole in the writing for the present review. For impacts affecting the recreational level in con, the coaching style and typical strategies were seen concerning implementation (Horn, 2008). Oneself propelled were created, social help and objective exercises, in accomplishing an errand (confirmation and capacity) of the gathering and affiliation execution requested by the gatherings, points, and reason on the measure of tracks and help (Ryan \& Tipu, 2013).

The impression of Badminton players for the effect of democratic coaching was estimated through coaching efficacy scale CES that indicated the comparable component structure as the first scale. Applying an equivalent methodology, Myers alongside associates (Myerss et al., 2009) additionally followed the instructing viability Scale to measure players' evaluations of their coaches' competence. Indistinguishable items of the scale from in particular were used, requesting that players determine how their coach was capable, as we requested that players demonstrate how successful the democratic coach is or how to influence the down technique of badminton players during badminton competitions. A creation that tends to affect of instructing is the adequacy of training. Effect of instructing authority styles has been ending up being a scale to which the coaches think about an idea of having could affect the learning and execution of related players' game strategy, method, rivalry, and character working of the player. Effect on game system indicates the self-assurance or capacity of mentors or coaches in their ability to prepare and control their players to a triumphant performing position during the competitions (Kavussanu et al., 2008).

The discoveries of the current examination show the headway in the field of information with as of late investigation of mental foundations of the view for discovering the realities related with the effect of coaching on game strategy in the field of College level Badminton competitions while taking the coaching efficacy scale (Feltz et al., 1999), altered by Myers, et, al; 2009 as a restricted wellspring of examination. Even though the significance of the effect of coaching for profoundly mutually dependent games like Badminton has been created in the writing, these outcomes add to tolerating its mental foundations and this is the first historically speaking investigation on Badminton Coaching viability at Sukkur Region Sindh. In such a manner understanding the information on fair training and its effect on players can have a diverse tendency for coaches engaged with the ability improvement of players.

Resultantly sports authorities and exploration researchers would be fit for recommending mentors to receive popularity based on instructing initiative style especially at Inter-class/ interdepartment, Inter-collegiate and inter-varsity level of competition to support up the players to the 
more significant level of rivalries. A mentor must have a capacity to comprehend the requirements of the player to use their maximum capacity and to fortify mentor player relationship. While; in badminton match-up the knee injury issues were additionally featured by Shah et al., (2014) which likewise key centered by the mentor of the game. Along these lines; the commitment of a mentor is to advance the execution level of players and to make a domain as a device to improve and the discoveries of this examination will allow me to give this exploration to the mentors to apply same inside their wards to accomplish the exhibition-related objectives in sports.

\section{Conclusion}

An examination of Badminton coaching especially the democratic coaching style which is treated as an approach to train the player over Pakistan and worldwide yet at this stage was to see its effect on the game strategy of College/ University level Badminton players during competitions. The current assessment recognizes that there was a positive effect of democratic coaching style on the game strategy of Badminton players at Sukkur region Sindh, hence the main objective of the study achieved here.

\section{Recommendation}

While; analyzing this exploration and future examination points, detailed comprehension of the coaching, the effect of coaching, coaching style could be guaranteed.

- It is suggested that; the current investigation could be utilized by the coaches and the trainers or by any person concerned with the organization of sports to upgrade the degree of execution concentrating on the game strategy of the players especially badminton at the college or university level including all games.

- The training programs to implement this way of coaching at the college/university level for Badminton players be introduced to improve the skills of the players for their better game

\section{References} strategy in the tournaments.

Alam, F., H. Choudhary, Ch. Thepadungporn, A. Subic \& Khan M.M.K. (2009). International School of Aerospace, Mechanical and Manufacturing Engineering and built environment, Central queen's land University Rockhampton Australia. J. Mech. and Material Eng., 4, 266-272.

Campbell, T., \& Sullivan P.J. (2005). The effect of a standardized coaching education program on the efficacy of novice coaches. Avante. 11: 38-45.

Christensen, B.T., \& Ball, L.J. (2016). Dimension of creative evaluation: Distinct design and reasoning strategies for aesthetic, functional, and original judgments. design studies, 45(PA), 116-136.

Cote, J., \& Gilbert, W. (2009). An integrative definition of coaching effectiveness and expertise. International Journal of Sport Science and Coaching, 4, 307-232.

Dess, G. G., \& J.C. Picken. (2000). changing roles: Leadership in the $21^{\text {st }}$ century. Organizational Dynamics, 29 (4): 18-33.

https://en.wikipedia.org/wiki/Badmintonhttps://www.thebadmintonguide.com/badmintonintroduction/

Farrow, D. \& B. Abernethy. (2003). Do expertise and the degree of perception-active coupling affect natural anticipatory performance, Perception, 32: 1127-1139.

Feltz, D.L., Chase, M.A., Moritz, S.E., \& Sullivan, P.J. (1999). A conceptual model of coaching efficacy: Preliminary investigation and instrument development. Journal of Educational Psychology, 91(4), 765-776.

Horn, T.S., (2008). Coaching effectiveness in the sport domain. In: T.S. Horn (Ed.), Advances in sport psychology (pp. 239-267). Champaign, IL: Human Kinetics.

Jowett, S. (2007). Inter-dependence analysis and $3+1 \mathrm{Cs}$ in the coach-athlete relationship. In: S. Jowett, \& D. Lavallee (Eds.), Social Psychology in Sport (pp.15-28). Champaign, IL: Human Kinetics.

Jowett, S., \& Cockerill, I.M. (2003). Olympic medallists' perspective of the athlete-coach relationship. Psychology of Sport and Exercise, 4, 313-331.

Jowett, S., \& Cockerill, I.M. (2002). Incompatibility in the coach-athlete relationship. In I.M. Cockerill (Ed.) Solutions in sport psychology. Pp.16-31. 
Jung, J., Y.J. Ahn, L.W. \&.Kang. (2008). A novel approach to investigating protein/protein interactions and their functions by TAP-tagged yeast strains and its application to examine yeast transcription machinery. J. Microbiol. Biotechnol. 18(4): 631-8.

Keatlholetswe, L. \& Malete, L. (2019). Coaching Efficacy, Player Perceptions of Coaches' Leadership Styles, Team Performance in Premier League Soccer. Res. Q. Exerc. Sport. Vol. 90. Pp. 71-79.

Kavussanu, M., I.D. Boardly, N. Jutkiewiez, S. Vincent, \& Ring C. (2008). The Coaching efficacy and coaching effectiveness. The Sports Psycho. 22(4): 383-404.

Khan, M.S., I. Khan, Q.A. Qureshi, H.M. Ismail, H.M. Rauf, A. Latif \& M. Tahir. (2015). the Styles of Leadership: A Critical Review. 5(3): 87-92.

Kristiansen, E., Tomten, S. E., Hanstad, D. V., \& Roberts, G. C. (2012). Coaching communication issues with elite female athletes: Two Norwegian case studies. Scandinavian Journal of Medicine \& Science in Sports, 22, 156-167.

Martens, R. (2012). Successful coaching ( $4^{\text {th }}$ edition) Champaign, IL: Human Kinetics.

McDonnell, J. (2016). Scaffolding Practices: A study of design practitioner engagement in design education. Design studies, special issue; design review conversations, 45 (part A), pp 9-29.

Myers, N.D., E.W. Wolfe \& Feltz D.L. (2009). An evaluation of the Psychometric Properties of exercise science, 9(3), 133-105.

Magee, J.; Galinsky, A.D. (2008). Social hierarchy: The self-reinforcing nature of power and status. Acad. Manag. Ann. Vol. 2, pp. 351-398. [CrossRef]

Oberle, E. \& Schonert-Reichl, K.A. (2016). Stress contagion in the classroom? The link between classroom teacher burnout and morning cortisol in elementary school students. Soc. Sci. Med. 159. Pp.30-37.

Pilus, A.H.M. \& Saadan R. (2009). Coaching leadership styles and athlete satisfaction among Hockey team. J. Human Capital Develop. 2(1), 77-87.

Ryan, J.C., \& Tipu S.A. (2013). Leadership effects on innovation propensity: A two-factor full range leadership model, Journal of Business Research, 66, 2116-2129.

Shah, S.A.A., Muhammad A.A., \& Muhammad R.Q. (2014). The occurrence of knee injury in badminton: a case study of Sindh. The Shield, 09: 21-30.

Shariff, A.H., George, J., \& Ramlan, A.A. (2009). Musculoskeletal injuries among Malaysian badminton players. Singapore Med. J., 50(11), 1095-1097.

Smith, R.E. (2010). A positive approach to coaching effectiveness and performance enhancement. In: J. M. Williams (Ed.), New York: McGraw-Hill. Applied sport psychology: personal growth to peak performance (pp. 42-58).

Van Duijvenvoorde, A.C.; Peters, S.; Braams, B.R... \& Crone, E.A. (2016). What motivates adolescents? Neural responses to rewards and their influence on adolescents' risk-taking, learning, and cognitive control. Neurosci. Biobehav. Rev. Vol. 70, 135-147. [CrossRef] 